\title{
Deleuze, Strauss y una brecha en medio de Spinoza
}

\section{Deleuze, Strauss and a gap in the middle of Spinoza}

\author{
JULIÁN FERREYRA \\ UBA/Paris X/CONICET
}

Resumen. Proponemos confrontar el pensamiento de Gilles Deleuze y Leo Strauss a partir de las disímiles interpretaciones que estos dos influyentes filósofos del siglo xx han hecho de la ontología política de Spinoza. Ambos comparten una problemática común: cómo se relacionan la sustancia y los modos existentes. Pero donde Strauss realiza un llamado a la Revelación y el mandato de amar al prójimo para colmar la brecha y evitar que la sabiduría sea sinónimo de indiferencia ante el sufrimiento de la multitud, Deleuze recurre a una propuesta de lectura de la teoría del modo finito que permite distinguir el punto de vista de la Eternidad de aquel de la Duración, sin por eso dejar a los modos finitos librados al azar de los encuentros, es decir, permitiéndoles encontrar su conatus en la potencia divina.

Palabras clave: Eternidad, duración, Política, Spinoza, Strauss.
Abstract. We propose to study the thought of Gilles Deleuze and Leo Strauss from the stand point of the opposed interpretation than this two influential philosophers of the twentieth century have made of the political ontology of Spinoza. Both share a common problematic: how substance and existent modes do relate. But where Strauss makes a call to Revelation and the demand to love one's neighbour to fulfil the gulf, and avoid that being wise means to expel the suffering of the multitude from the sphere of one's own life, Deleuze posits an interpretation of the theory of finite modes that allows us to distinguish the stand point of Eternity from that of Duration, without by doing so subjecting finite modes to the random order of encounters, that is, allowing them to find their conatus in divine power.

Key words: Eternity, duration, politics, Spinoza, Deleuze, Strauss.

La palabra de utopía designa entonces esta conjunción de la filosofía o del concepto con el medio presente: filosofía política

Deleuze y Guattari, ¿Qué es la filosofía?

La distancia en filosofía, y especialmente en filosofía política, entre las diversas tradiciones se torna por momentos inconmensurable. Se produce así un aislamiento en dimensiones geográficas, temporales e ideológicas estancas. Se pierde así la tensión, la posibilidad del encuentro y el consiguiente acontecimiento de producción de pensamiento. Intentaremos en estas páginas habilitar un encuentro. Dadas las malas relaciones que el pensamiento filosófico tiene con las generalidades, se 
trata de escoger dos pensadores concretos y abordar su disparidad. Se trata de dos figuras por demás inconmensurables: Leo Strauss (Alemania, 1899-1973) y Gilles Deleuze (Francia, 1925-1996). Desde la perspectiva filosófica de Deleuze, Strauss aparecería a primera vista como un exponente de la filosofía de la representación y la trascendencia, de la imagen dogmática, ortodoxa o moral del pensamiento: «las bodas monstruosas donde el pensamiento "reencuentra" al Estado, reencuentra "a la Iglesia", reencuentra todos los valores del tiempo que ha hecho pasar sutilmente bajo la forma de un eterno objeto cualquiera, eternamente bendecido» ${ }^{1}$. Recíprocamente, desde el ángulo de la perspectiva filosófica de Strauss, Deleuze aparecería como un representante de la filosofía moderna, un liberal, un ateo y un nihilista, en suma, una de esas figuras que lo llevaron a preguntarse «si la autodestrucción de la razón no fue el desenlace inevitable del racionalismo moderno distinguido del racionalismo premoderno, especialmente el judeo-medieval y su fundamentación clásica (aristotélica y platónica)» ${ }^{2}$.

Cabría incluso extrapolar una frase de Strauss, y decir que las posiciones del filósofo alemán y el francés «parecen estar directamente en oposición sin posibilidad de acuerdo o, lo que es lo mismo, sin posibilidad de crítica genuina» ${ }^{3}$. En efecto, el riesgo que este tipo de puestas en contacto suponen suele ser el de hacerlos hablar de lo mismo cuando hablan de cuestiones que nada tienen que ver entre sí, o de buscar acuerdos donde éstos no podrían nunca existir; en ambos casos, sin posibilidad de crítica genuina.

Pero se trata de buscar un punto de encuentro de ambos pensamientos que genere, que pueda generar, un nuevo brote en el pensar. Buscaremos ese punto de encuentro (que no implica por cierto un punto de acuerdo) en un mismo problema que preocupa a ambos, que a los dos les parece relevante, vital, urgente, aún cuando el camino que intentan recorrer para dar respuesta a tal problema sea diametralmente opuesto. Es el problema de cómo seguir pensando una vez que los fundamentos y la particular racionalidad de la Weltanschauung moderna se nos aparecen como radicalmente insatisfactorios. Para uno, en el escenario de entreguerras en la primera mitad del siglo $\mathrm{XX}^{4}$. Para el otro, en el seno del capitalismo «aparentemente triunfador» de la segunda mitad de ese siglo ${ }^{5}$. Para nosotros, en el seno de la crisis de la omnipotencia de la economía del mercado.

Ese problema puede ser adecuadamente analizado en torno al estudio que Deleuze y Strauss emprenden del filósofo holandés del siglo XVII Baruch de Spinoza, cada uno desde su geografía, época y motivación. En la segunda mitad de la década del 20, Strauss se concentra en el estudio de Spinoza. Le dedica sus lecciones en la Casa de Libre Enseñanza Judía de Frankfurt am Main entre 1925 y 1928 y dos artículos publicados en 1924 y 1926. Resultado de esas investigaciones es su primer libro, Die Religionskritik Spinozas als Grundlage seiner Bibelwissenschaft Untersuchungen zu Spinozas Theologisch-Polischem Traktat de 1930. En 1932 aparece el breve «Testamento de Spinoza». Strauss vuelve al filósofo holandés en 1948, y finalmente escribe en 1965 un prólogo a la edición en inglés de su libro de 1930 que será, según Strauss mismo declara, su «testamento intelectual» $^{6}$. Deleuze, por su parte, publica Spinoza et le problème de l'expression, en 1968, y Spinoza, philosophie pratique, en 1981. También ocupó en él varios cursos en la Universidad de París VIII, entre el final de la década del 70 y el inicio de la del $80^{7}$.

Pero no se trata, simplemente, de la convergencia en el interés por un mismo 
autor; de ser simplemente eso, la cuestión distaría de tener interés filosófico. Ocurre que la visión que ambos proponen de Spinoza es contrapuesta, tanto en lo valorativo como en lo interpretativo: para Strauss se trata de un rival cuyo problema es defender la razón individual y cuestionar la palabra revelada; para Deleuze, se trata de una fuente de inspiración, cuyo problema es, en todo caso, no llevar el pensamiento de la inmanencia hasta sus últimas consecuencias. Pero permaneceríamos aún en la oposición sin posibilidad de acuerdo, sin posibilidad de crítica genuina. Lo interesante, y lo que motiva este artículo es que entendemos que las críticas que Strauss efectúa a Spinoza interpelan el pensamiento de la inmanencia de Deleuze, con el condimento de ubicarlo en el lugar opuesto en el mapa de la filosofía al cual habitualmente se le asigna. En efecto, Deleuze es acusado habitualmente de irracionalista y anti-humanista ${ }^{8}$. Sin embargo, si pensamos que las críticas de Strauss a Spinoza lo alcanzan, la crítica sería por racionalista y humanista. Curioso giro, que nos proponemos estudiar en las páginas que siguen.

\section{Strauss abre la brecha}

Ya en su primer escrito sobre Spinoza, Strauss pone en claro los motivos de su cuestionamiento, que coinciden con su caracterización crítica de la modernidad: para el holandés sería «autoevidente y en acuerdo con todo su punto de vista dar precedencia al conocimiento autónomo [Erkenntnis] por encima de la autoridad de la Escritura» ${ }^{9}$. Dos años más tarde será todavía más explícito al indicar que Spinoza y el iluminismo coinciden en su objetivo verdadero: «estar en contra de la religión revelada en todas sus formas» ${ }^{10}$. El rechazo de la Revelación y la Ley que ella contiene es la característica de la modernidad ${ }^{11}$, y «el documento clásico del ataque racional o secular a la Revela- ción» es el Tratado Teológico-Político ${ }^{12}$. Para Spinoza, y el gesto moderno-humanista en general, la revelación original es la razón y por lo tanto «toda revelación posterior debe ser medida por ese estándar. En la medida en que la Escritura contradice a la razón, se trata de una invención humana» ${ }^{13}$. Es la deriva humanista de la modernidad: humanista en tanto pone como origen o fundamento la razón humana, humanista en tanto considera a la Revelación como una invención humana, solamente humana. Se trata de una deriva trágica, ya que implica el abandono de lo secular a la miseria que implica la pérdida del orden de lo sagrado.

El pensamiento premoderno, tanto la filosofía antigua como la tradición bíblica o la filosofía judeocristiana, más allá de sus profundas diferencias, entendía la Ley como algo objetivo, como un orden eterno que el hombre recibe de fuera, de la Naturaleza o de Dios, y que debía obedecer (...) Strauss nos muestra que en el origen de la filosofía (política) moderna... se encuentra, en cambio, la reivindicación de un orden inmanente y liberado del yugo externo de la Ley ${ }^{14}$.

De acuerdo con Rivera García, el verdadero objetivo del proyecto moderno es, según Strauss, el levantamiento de instituciones completamente inmanentes ${ }^{15}$. Sin embargo, Spinoza, siendo un «heredero de la modernidad», permanece para el alemán al mismo tiempo en la tradición medieval en tanto intenta restaurar la concepción tradicional de contemplación; «uno no puede pensar en conquistar la naturaleza si la naturaleza es lo mismo que Dios» 16. Justamente esto produce una brecha en el pensamiento de Spinoza.

Hay una brecha (Kluft), dice Strauss ${ }^{17}$. Hay una brecha, repite, tres líneas después. Se trata de la brecha entre los sabios y la multitud, una brecha «creada por el interés en la teoría, entre los sabios y la multitud, que hace de los sabios esencialmente espectadores de la 
vida de la multitud. Para los sabios, la multitud se vuelve objeto de la teoría» ${ }^{18}$. El saber que la filosofía abre, el saber al cual la filosofía nos permite acceder, aquello que según Strauss la filosofía para Spinoza pretende ser, se transforma en una terrible indiferencia ante el sufrimiento de la multitud. El hombre, como todo modo existente, persevera tanto como le es posible por permanecer en la existencia: tal es el conatus. Pero la brecha hace que haya caminos divergentes en tal perseverancia, según se trate del sabio o la multitud, el filósofo o el vulgo: «hay dos caminos para la lucha del hombre por la auto-preservación: el camino de la multitud guiada sólo por sus pasiones y el camino del sabio guiado por la razón» ${ }^{19}$. Guiada por las pasiones, la multitud carece de conocimiento racional; la facultad que orienta sus acciones es la imaginación, es decir, el conocimiento inadecuado que emerge como respuesta al orden azaroso de las imágenes aisladas que golpean la mente ${ }^{20}$. Todo es azar, todo es fortuito, todo es gratuito, nada tiene sentido para la multitud, que se encuentra "sometida y esclava a la buena o mala suerte que puede caer sobre ella» ${ }^{21}$. Los miembros de la multitud son «pobres diablos tratando de defender sus pellejos» ${ }^{22}$. Es el nihilismo. La multitud que se enfrenta con las fuerzas que constituyen su derrotero por la tierra como un niño que chapotea en el mar:

¿Qué quiere decir chapotear? Es muy simple, la palabra indica bien que son relaciones extrínsecas: ahora la ola me golpea, luego me arrastra; son los efectos del choque. No conozco nada de la relación que se compone o se descompone, sólo recibo los efectos de partes extrínsecas. Las partes que me pertenecen son sacudidas, reciben el efecto del choque de las partes que pertenecen a la ola. Ahora me río, luego lloriqueo, según que la ola me haga reír o me aporree. Estoy en los afectos-pasión: «iOh, mamá, la ola me ha tumbado!» 23
La descripción de Deleuze del conocimiento inadecuado, imaginativo, se aplica bien al conocimiento que Strauss considera característico de la multitud. Los fieles congregados en una iglesia no son diferentes de los niños jugando con las olas: la religión, la superstición, son el modo en que la multitud está necesariamente condenada a concebir su existencia $^{24}$. ¡Oh, señor cura, la ola me ha tumbado! Frente a esa vida sometida a las pasiones (y, lo sabemos, en la realidad efectiva, son siempre más los golpes que las surfeadas) el sabio spinozista, tal como Strauss lo entiende, observa a la multitud chapoteando en medio de la miseria y el dolor de la existencia con la misma impasibilidad con la que observaría a un escarabajo tratando de salir del agua del excusado. Su sabiduría (la teoría) no lo implica, en ningún momento, en ninguna medida, con la vida de la multitud. «La teoría y la religión son posibilidades opuestas para el ser humano que se oponen radicalmente la una a la otra como la fuerza a la impotencia, la libertad a la esclavitud, la actitud espiritual a la carnal» ${ }^{25}$. Strauss interpeta la inscripción en el sello con el que firmaba Spinoza "caute» como el signo de la precaución que los filósofos tienen que tener en su relación con la multitud ${ }^{26}$. La «independencia» que Strauss considera el testamento de Spinoza es entonces la consagración de la brecha ${ }^{27}$ : precaución, distancia respecto de la multitud.

En numerosos pasajes del artículo de 1926 Strauss reitera que el interés de Spinoza es exclusivo por el conocimiento teórico, que no solamente es «el más alto interés de los seres humanos» sino que además «absorbe y desprecia todo otro interés» que queda por principio devaluado ${ }^{28}$. En definitiva, se tratará de una filosofía exclusivamente teórica, y nunca de una filosofía práctica. Ocurre que Deleuze titulará uno de los libros que le dedica 
al filósofo holandés Spinoza, filosofía práctica. ¿Dónde está la fuente del malentendido? En un problema específicamente ontológico y de raíz clásica: la distinción entre lo que es «en sí» y lo que es «en otro», y la interpretación de la forma en la cual Spinoza recupera dicha distinción. Existe entonces una antítesis entre el conocimiento filosófico de la sustancia, de lo que es «en sí», y del conocimiento relativo a lo existente, es decir, de los modos, que son «en otro». Todo el conflicto político, la impotencia política de la filosofía spinozista reposa en una oposición ontológica:

Un contraste que en definitiva reposa en la oposición ontológica entre lo total e imperecedero que es en sí, y lo parcial y transitorio que es en otro. Entre ambos no hay término medio... Pues Spinoza se mantiene en la abrupta antítesis entre la razón y la imaginación ${ }^{29}$.

La tensión que Strauss señala entre lo que es en sí y lo que es en otro, la tensión entre esencia y existencia, entre eternidad y duración, es en efecto una de las claves de la ontología de Spinoza, como él mismo señala en su Carta XII a Meyer:

Concebimos la existencia de la sustancia de forma enteramente diferente a la existencia de los modos, y de aquí nace la diferencia entre la Eternidad y la Duración. Por medio de la duración, en efecto, no podemos explicar más que la existencia de los modos, mientras que la de la sustancia se explica por medio de la Eternidad, que es fruición infinita del existir o, a despecho de los latinistas, del ser ${ }^{30}$.

Esta diferencia entre la manera de concebir la existencia de los modos y la de la sustancia es fundamental para todo pensamiento práctico cuya base se intente establecer en la ontología de Spinoza. Los modos duran: la duración es entonces el problema práctico por excelencia. La sustancia es pura fruición infinita del existir en la Eternidad: el conocimiento de la sustancia es ajeno en principio a los problemas emergentes de la duración. Y es en la importancia otorgada a tal diferencia donde Strauss y Deleuze se reúnen:

Si consideramos las esencias de modos finitos, vemos que ellas no forman un sistema jerárquico donde las menos potentes dependerían de las más potentes, sino una colección actualmente infinita, un sistema de implicaciones mutuas donde cada esencia conviene con todas la otras y donde todas las esencias están comprendidas en la producción de cada una (...) Sin duda un modo existente finito remite a otra cosa que el atributo; el encuentra su causa en otro modo existente; éste en otro, al infinito. Pero, para cada modo, Dios es la potencia que determina la causa a tener tal efecto ${ }^{31}$.

Las esencias de los modos finitos convienen todas con todas las demás. Dios las produce en la producción de cada una de ellas. Para los modos, la esencia no implica la existencia. Ello ocurre solamente para la sustancia; sólo para Dios la esencia equivale a la existencia. En la ontología de Spinoza, como es de conocimiento general, no hay más que una sola sustancia. Unidad de la sustancia, multiplicidad de los modos. Entonces, justamente, para los modos, la esencia no implica existencia: no hay una presión a la existencia por parte de las esencias de modos (como sí ocurre, por ejemplo, en la ontología de Leibniz). La esencia de modo no-existente no carece de nada. El modo existente no puede, por lo tanto, encontrar su causa en su esencia. La causa debe estar en otra parte: «en otro modo existente». Esa oposición entre esencia y existente produciría la brecha que Strauss encuentra en la filosofía de Spinoza. El conocimiento de la Sustancia (la filosofía a la cual sólo los sabios tienen acceso) y la vida de los modos existentes (la superstición de la multitud) no tendrían nada en común. Así lo entiende, como hemos visto, Strauss. 
Si aceptamos el corte, la brecha entre la sustancia y los modos, entre las esencias y los existentes, el mundo, nuestro mundo, nuestro siglo quedaría librado al azar: los cuerpos y las almas se definirían solamente por «sus encuentros y sus choques al azar» ${ }^{32}$. Por su parte, la sustancia no se abriría al mundo, replegada sobre sí misma. Esta brecha debe ser colmada si no queremos que el spinozismo se transforme en una mera justificación de la inequidad para cínicos afortunados. Strauss aspira a colmarla, pero para hacerlo recurre a una instancia trascendente: la concepción de Dios como rey y el consecuente mandato de amar al prójimo; tal mandato nunca se puede encontrar en la razón humana, no es inmanente a nuestra vida y nuestro mundo, sino que debe haber sido gravado en nuestros corazones por Dios como instancia trascendente. El conocimiento racional de Dios que nos ofrece Spinoza es indiferente al sufrimiento de la multitud porque carece del elemento que sólo puede venir de Dios: el mandato de amar al prójimo ${ }^{33}$. Según Strauss, el rechazo de la Revelación por parte de Spinoza impide abandonar la única mediación posible entre esa trascendencia y nuestra vida en el mundo secular. Strauss ve en las dudas respecto a la Weltanschauung moderna que señala en «El testamento de Spinoza» la posibilidad de volver a la religión revelada.

Ocurre que la solución de Strauss implica dar por tierra la teoría de la inmanencia de Spinoza. Desde el punto de vista de Deleuze, eso sería como tirar el bebé con el agua del baño. La filosofía de la inmanencia, para él, no lleva al nihilismo. Todo lo contrario: sólo la filosofía de Spinoza puede resolver el problema político, el problema de la existencia. Tenemos un problema en nuestra existencia, no hay ninguna justificación acrítica de lo dado, ninguna construcción del «mundo político desde la distancia de la con- templación, afirmando las potencias que lo forman, "amándolas" a la manera del amor fati, pero expulsándolas de la esfera de su propia vida» ${ }^{34}$, como Strauss acusa a Spinoza ${ }^{35}$. Todo lo contrario: Deleuze asume que estamos en el fango, que la situación política contemporánea nos daña, que somos miserables. En ese sentido, Deleuze no sería tampoco moderno y acordaría con Strauss en su crítica al progreso civilizatorio:

Proporcionalmente con el éxito del esfuerzo sistemático de liberar completamente al hombre de los lazos no humanos, la duda se incrementa respecto a si este objetivo no es quimérico - si acaso el hombre no se ha vuelto más miserable en proporción al progreso sistemático de la civilización ${ }^{36}$.

Para Antonio Lastra, el secreto de la filosofía de Strauss radica en la resignación ante «el hecho de que no todo sea humano: la parcialidad de lo humano en el universo es el quicio insuperable del humanismo» ${ }^{37}$. Si tal es efectivamente el secreto, el mismo es compartido por Deleuze: «Sexo no humano, son las máquinas deseantes, los elementos maquínicos moleculares, sus agenciamientos y sus síntesis» ${ }^{38}$. Se trata de los lazos no humanos sin los cuales estamos condenados a la servidumbre de las máquinas sociales, molares y humanas.

El punto de vista filosófico consiste precisamente en transformar las condiciones miserables de la existencia a partir de la comprensión de las condiciones de posibilidad de nuestra existencia. Lejos de no tener compasión ni corazón por el pueblo, la filosofía práctica que Deleuze construye a partir de Spinoza intenta arrancar a la multitud de la miseria. Y no se trata de lo meramente humano, sino de algo ultra-humano, divino (aunque no trascendente): el acceso al conocimiento de los modos tal como son en Dios (el universo de las máquinas deseantes). 
Pero al mismo tiempo, se trata de evitar la escisión de los modos y la sustancia (o de lo molar y lo molecular, o de lo humano y lo no humano), ya que ello implicaría abandonar a los hombres a los choques y al azar (abandonarnos, en definitiva, al nihilismo). La cuestión en Deleuze no es cantar la alabanza a los flujos, las máquinas deseantes y lo molecular: y esto no es jamás tan claro como en los textos que escribe en torno a Spinoza. En ese sentido, resolver las críticas de Strauss es clave. Desde una perspectiva deleuziana, tal resolución implica, por una parte, no permanecer indiferente ante el riesgo de ser moderno en el peor de los sentidos, en el sentido de aceptar «el sometimiento de lo público estatal a los intereses de las distintas corporaciones y facciones económicas, a las presiones de sectores y actores políticos, culturales, religiosos, societales de variado tipo, que invocan abstracciones universalistas para promocionar sus perspectivas particularistas» ${ }^{39}$. No provocar una brecha que abandone al hombre a los choques de las corporaciones económicas: he ahí la importancia de dar cuenta de las críticas de Strauss. Pero, por otra parte, tal resolución acarrea el desafío de hacerlo presentando una solución alternativa a la de Strauss, es decir, una solución que no sea «reaccionaria», que no recurra a un regreso al pensamiento premoderno, aún cuando este regreso sea posible ${ }^{40}$, temiendo que la trascendencia, incluso con el contenido concreto de la Revelación, no sea más que una abstracción universalista. La apuesta es concebir un Dios que no sea trascendente, y que por lo tanto no precise de la mediación de la Revelación. Rechazar la Revelación y el «verdadero bien» no implica, por lo tanto, si esto se logra, que la multitud resigne la libertad, ni que el mundo resigne lo ultra-humano que da sentido a la vida ${ }^{41}$.

Ahora, se nos abre la pregunta por el punto en el que ambas filosofías se tor- nan irreconciliables. ¿Por qué la apuesta deleuziana por la imnanencia y no por la trascendencia? ¿Por qué la Etica de Spinoza y no la Biblia? Strauss no deja de tener razón:

La Etica de Spinoza intenta ser un sistema pero no lo logra; la presentación clara y distinta de todo que realiza permanece fundamentalmente hipotética. Como consecuencia, su status congnitivo permanece fundamentalmente hipotético. Es indudable que Spinoza no puede negar legítimamente la posibilidad de la Revelación. Pero aceptar que esa Revelación es posible significa aceptar que la presentación filosófica y el modo de vida filosófico no son necesariamente, ni evidentemente, la verdadera presentación y el modo correcto de vivir: la filosofía, en su gesta por el conocimiento evidente y necesario, permanece en sí misma una decisión no evidente, o un acto de la voluntad, tanto como la fe ${ }^{42}$.

\section{Apología del punto de vista del existente finito}

El sabio spinozista es el que logra ubicarse en la perspectiva divina, la perspectiva de las esencias tal como éstas son en Dios, y contemplar a partir de esta perspectiva la existencia de los modos. El sabio comprende que «todas las esencias convienen con todas las otras» ${ }^{43}$. En tanto intensivas, las esencias pueden existir todas al mismo tiempo en acto. Desde el punto de vista del conocimiento, de la filosofía teórica, especulativa, se trata de una verdad que no se presta a ninguna objeción: la Sustancia «ama» los modos en que se expresa al modo del amor fati. No hay lucha ni antagonismo. No hay lugar par revoluciones, siquiera para reformas. Tampoco para la conservación o la reacción. No hay lugar entonces para la política. La acusación de Strauss a la indiferencia del sabio spinozista frente al sufrimiento de la multitud es justa. «El Dios de Spinoza está más allá del bien y del mal... El bien y el mal difieren sólo desde un punto de vista meramente humano; 
teológicamente la distinción no tiene sentido. Las pasiones malvadas son malvadas sólo desde el punto de vista de la utilidad humana» ${ }^{44}$. Pero ocurre que el sabio así concebido tiene sólo un conocimiento de las esencias que, sin embargo, no explican nuestro mundo, ellas no son la causa de la existencia de los modos:

La existencia del modo tiene pues por causa otro modo, él mismo existente. Pero esta regresión al infinito no nos dice para nada en qué consiste la existencia. De todas maneras, si es verdad que un modo existente «tiene necesidad» de un gran número de otros modos existentes, podemos presentir ya que él mismo está compuesto de un gran número de partes, partes que le llegan de más allá, que comienzan a pertenecerle desde que existe en virtud de una causa exterior, que se renuevan bajo el juego de las causas, mientras exista, y que dejan de pertenecerle a partir del momento en que muere. Ahora podemos decir en qué consiste la existencia del modo: existir, es tener actualmente un número muy grande de partes $^{45}$.

La existencia consiste en tener un número muy grande de partes extensivas. Tenerlas, no agrega nada a la perfección de la esencia de un modo. El pasaje a la existencia, la duración de tal existencia, que el umbral de este grado de potencia sea el mínimo o el máximo, nada de ello tiene ningún tipo de importancia desde el punto de vista de la Sustancia, el punto de vista del sabio spinozista caracterizado por Strauss. La existencia del modo no está fundada en la necesidad de Dios, sino en la contingencia y el azar de los encuentros de las partes extensivas, de los choques y entrechoques. Indiferencia causal, entonces, de la Sustancia respecto a la existencia de los modos.

Deleuze subvierte el esquema metafísico del spinozismo ortodoxo al plantear que el conocimiento de los modos tal como éstos son en Dios no agota la letra de la obra de Spinoza, y postula que todo cambia cuando el emplazamiento es el punto de vista de los existentes finitos. Es verdad que nuestra existencia es el fruto de los encuentros, de los choques, de los «grandes azares y sorprendentes encuentros») que componen la historia de la humanidad. Pero, una vez que el pasaje a la existencia tiene lugar, una vez que tenemos actualmente un número muy grande de partes, la lucha por la existencia consiste en no renunciar a ellas: «ustedes, en tanto existen, tienen partes extensivas que los componen. No es cuestión de renunciar a ellas» ${ }^{46}$. Esta lucha es el famoso conatus, el esfuerzo por perseverar en la existencia. No se trata de dos tipos de hombres diferentes (sabios, multitud) radicalmente diferenciados según los «dos caminos para la lucha del hombre por la auto-preservación» (teoría, religión), como aparece según la perspectiva straussiana ${ }^{47}$. Desde la perspectiva deleuziana del pensamiento de Spinoza, una vez dada la existencia, el existente lucha por conservar sus partes extensivas. La fuerza para llevar a cabo esta lucha, lo veremos, proviene de la esencia, pero no la existencia misma. Y he aquí la aporía: el sabio, también él, es un modo existente finito. Debe entonces luchar por la existencia. Incluso si, en tanto sabio, él se caracteriza por la posesión de ideas adecuadas, su punto de partida, también, es lo inadecuado. Deleuze habla del asombro «empirista»: «que los hombres lleguen a veces a comprender lo verdadero, a veces a comprenderse entre ellos, a veces a liberarse de lo que los encadena» ${ }^{48}$. La pregunta acerca de si existe una sabiduría práctica, un conocimiento no imaginativo relativo al punto de vista de los modos existentes, se transforma en una pregunta clave para la problemática aquí planteada. La respuesta de Strauss es categórica: no. Y la consecuencia que se desprende de ello: «independientemente de la convención humana, no hay nada justo ni injusto, no hay deber ni culpa» ${ }^{49}$. Ocurre que, la sali- 
da que Strauss propone para esta caída en el nihilismo es una instancia trascendente: «el Dios bíblico forma la luz y crea la oscuridad, hace la paz y crea el mal» ${ }^{50}$. El desafío que enfrentamos aquí es señalar la posibilidad de una filosofía práctica de la inmanencia, a partir de la interpretación deleuziana de Spinoza. De ello trata la «teoría de la existencia» que Deleuze presente en Spinoza y el problema de la expresión.

\section{Teoría de la existencia}

Tener un gran número de partes extensivas. He aquí una primera aproximación a aquello que la existencia es. Como punto de partida. No hemos, sin embargo, avanzado más que un pequeño paso. Tenemos partes extensivas. Bien. Pero, ¿qué quiere decir, tener partes extensivas? Sin duda, no debe pensarse que se trate de una «propiedad privada» de nuestra esencia. La esencia del modo, en ese caso, sería interpretada como un «alma» que poseería el «cuerpo» que debe tener. Tal es la interpretación que Deleuze hace de la filosofía de Leibniz ${ }^{51}$. Pero, justamente, y en ese sentido, Deleuze busca evitar «darle a las esencias particulares spinozistas una interpretación leibniziana»» ${ }^{52}$. Las esencias de modos, si bien existen de manera intensiva, no son almas: «El alma, y también el cuerpo, tienen una esencia intensiva de una naturaleza totalmente diferente que sus partes extensivas» ${ }^{53}$. El alma (mens) en Spinoza es la idea de un cuerpo existente y tiene también la posibilidad de tener partes extensivas que le pertenezcan ${ }^{54}$. Existimos por las partes que nos componen: ése es el sentido de «pertenecer» para el spinozismo: y es verdad tanto para el cuerpo como para el alma (paralelismo). No hay ninguna interioridad. Nuestra existencia se agota en estas partes extensivas que nos componen y la relación particular en la que ellas entran.
Dado que no podemos decir de las partes extensivas que ellas «existen», puesto que «existir es tener actualmente una infinidad de partes extensivas», la correspondencia entre esencia y existencia no puede ser nunca «término a término». No hay esencia para cada parte extensiva, solamente para los conjuntos que ellas componen. Las «esencias singulares» son el primer elemento de la primera triada de la «teoría de la existencia en Spinoza» ${ }^{55}$. Esta esencia singular es un grado de potencia o de intensidad en un atributo de la sustancia divina. Pero, ya lo hemos visto, esta esencia no puede ser la causa de la existencia extensiva del modo, y esto en virtud de aquel viejo principio según el cual, «la existencia de un ser finito no deriva de su esencia»» ${ }^{56}$. La existencia de los seres finitos (almas y cuerpos, que tienen el mismo status ontológico) conforma el segundo elemento de la teoría de la existencia: la existencia particular, siempre compuesta de una infinidad de partes extensivas.

«¿Cómo pueden [las partes extensivas] corresponder a su esencia, o pertenecerle?», se pregunta Deleuze ${ }^{57}$. Se trata de una pregunta doble, que apunta a dos aspectos del problema de la existencia que por el momento permanecen sin explicación. Primero, ¿cómo pueden las partes extensivas pertenecer a un modo? $\mathrm{O}$, lo que es lo mismo, ¿cómo una infinidad de partes extensivas pueden componer una existencia particular? Es el problema del segundo elemento. De esta pregunta viene justamente a dar cuenta el tercer elemento de la teoría de la existencia: la forma individual, es decir, la relación característica, la relación de movimiento y reposo, en la cual las partes extensivas entran para dar lugar a la existencia del modo finito:

Las partes extensivas se determinan unas a otras, desde el exterior y al infinito; no tienen otra determinación que extrínseca. Un 
modo pasa a la existencia, no en virtud de su esencia, sino en virtud de leyes puramente mecánicas que determinan una infinidad de partes extensivas cualesquiera a entrar bajo tal relación precisa, en la que su esencia se expresa 58 .

En la medida en que la misma relación subsiste en el conjunto infinito de partes extensivas, el modo continúa existiendo. Las partes componentes pueden renovarse. Lo que constituye la existencia es una cierta relación entre estas partes. Vemos entonces que el tercer elemento, la forma individual o relación característica, resuelve el problema del segundo elemento, es decir, de qué manera las partes extensivas componen una existencia particular. Repetimos: la componen bajo una relación característica.

Que el hecho que determina a las partes a entrar bajo esa relación sea una causalidad extrínseca evita los inconvenientes que, desde el punto de vista de Spinoza y Deleuze, derivan de una «exigencia de la existencia» o una presión de corte leibniziano de las esencias con respecto a los existentes. Pero esta solución nos plantea un nuevo problema. Se trata del problema que venimos acarreando desde el principio de este trabajo: ¿no hay entonces un corte, una brecha ahora entre los modos y la Sustancia? El fin de la representación, ¿no libra los existentes al azar y a la ausencia de sentido, es decir, al nihilismo? Creo que el tercer elemento de la teoría de la existencia logra empezar a resolver nuestro problema.

La relación característica corresponde eternamente a una esencia modal. Pero, volviendo a la pregunta doble de Deleuze, ¿cómo pueden las partes extensivas corresponder a su esencia? Ya hemos visto que esta correspondencia no se realiza término a término. Y esto, podemos ver ahora, porque las esencias no son esencias de partes extensivas, sino esencias de relaciones. Es bajo esta relación que las partes extensivas pueden corresponder a una esencia. Y esto porque cada esencia de modo se expresa en una relación característica. Entonces, cuando las partes entran en una cierta relación en virtud de leyes puramente mecánicas, ellas corresponden a tal o cual esencia, la que se expresa en esa misma relación. $\mathrm{Si}$ el modo deja de existir, es decir, si las partes son determinadas por causas exteriores a entrar bajo otra relación, esa relación expresará también otra esencia.

Mientras que las esencias son eternas, los modos existentes pasan a la existencia, nacen, pero también pueden ser destruidos. Es en ese sentido que se dice que los modos duran. No hay distinción real entre esencia y existencia. La existencia de la cosa particular es la cosa misma, pero «ya no solamente en tanto que está comprendida en Dios, sino en tanto ella dura; en tanto está en relación con un cierto tiempo y un cierto lugar» ${ }^{59}$. Un tiempo y un lugar: el medio presente. Y es entonces en el medio presente que la lucha por la existencia podrá tener lugar. En tanto sus conceptos entren en conjunción con ese medio presente, la filosofía podrá tener su lugar en esa lucha.

\section{El orden de las relaciones: la ley de composición}

«No debemos, sobre todo, confundir las esencias y las relaciones, ni la ley de producción de las esencias con la ley de composición de las relaciones» ${ }^{60}$. No debemos sobre todo confundirlas. No confundir. Sobre todo no confundir, porque si confundimos las esencias y las relaciones, las esencias y los modos existentes, todo convendría con todo, y la posibilidad de la política, como ya hemos dicho, estaría perdida. No debemos permitir que la ansiedad de colmar la brecha nos haga caer en el otro extremo resolutivo y nos lleve a afirmar una continuidad absoluta. No confundimos, entonces, esencias y re- 
laciones. Y Deleuze añade: no confundir las esencias y las relaciones implica no confundir la «ley de producción de las esencias y la ley de composición de las relaciones». Se trata de dos órdenes diferentes. Hay que señalar, nos dice Deleuze «la irreductibilidad del orden de las relaciones al orden de las esencias mismas» ${ }^{61}$. Y esto por las razones que ya hemos subrayado: el orden de las esencias se define por una conveniencia total, pero el orden de las relaciones, en cambio, si bien todo se combina al infinito, no lo hace sin embargo de cualquier manera: «las relaciones no se componen de cualquier manera, no toda relación se compone con cualquier otra» ${ }^{62}$. He aquí por qué la lucha por la existencia tiene lugar. Debemos luchar por la existencia porque no todo se compone de cualquier manera con todo. Y, por la misma razón, esta lucha no es una lucha ciega y sin sentido: existen leyes, existe un nomos de la existencia. Hay leyes de composición de las relaciones, que afectarán el resultado del encuentro entre partes extensivas, que determinarán el resultado que determinados encuentros pueden tener. No se trata de puro azar.

$\mathrm{El}$ orden de las relaciones es bastante diferente [al orden de las esencias]: es un orden de composición según leyes (...) Este orden de encuentros determina pues efectivamente el momento en el que un modo pasa a la existencia (cuando las condiciones fijadas por la ley se cumplen), la duración durante la que existe, el momento en que muere o es destruido ${ }^{63}$.

Vemos entonces que hay leyes. De acuerdo a estas leyes, hay relaciones que se componen, y cuyo encuentro permite formar un cuerpo «todavía más compuesto»: hay entonces nacimiento, pasaje a la existencia de una nueva relación que no existía antes (a pesar de que la esencia de esa relación existiera de toda la eternidad). Pero hay también encuentros que implican la muerte para uno de los cuer- pos que se encuentran: es el caso de la relación «hombre» y la relación «arsénico».

Supongamos dos cuerpos compuestos: cada uno posee, bajo cierta relación, una infinidad de cuerpos simples o de partes. Cuando se encuentran, puede suceder que las dos relaciones sean directamente componibles. Entonces las partes de uno se ajustan a las partes del otro, bajo una tercera relación compuesta de las dos precedentes. Hay aquí formación de un cuerpo aún más compuesto que aquéllos de los que habíamos partido (...) Ese proceso es el de todo nacimiento o de toda formación, es decir, de todo paso a la existencia: algunas partes se encuentran bajo dos relaciones diferentes; cada una de esas relaciones corresponde ya a una esencia de modo; las dos relaciones se coronen de manera tal que las partes que se encuentran entran bajo una tercera relación, que corresponde a otra esencia de modo; el modo correspondiente pasa entonces a la existencia. Pero puede suceder que las dos relaciones no sean directamente componibles. Los cuerpos que se encuentra, o bien son indiferentes el uno al otro; o bien el uno, bajo su relación, descompone la relación del otro, por lo tanto destruye al otro cuerpo. Es el caso de un tóxico o un veneno, que destruye al hombre descomponiendo la sangre. Es el caso de la alimentación, pero en sentido inverso: el hombre fuerza las partes del cuerpo del que se nutre a una nueva relación que conviene con la suya, pero que supone la destrucción de la relación bajo la que el cuerpo existía precedentemente ${ }^{64}$.

Hay entonces una relación «hombre», una relación humana, que conviene con relaciones determinadas con las cuales esta relación compone, y otras que la descomponen. Y todo esto, siguiendo leyes, y no puro azar ${ }^{65}$. Es sin embargo «fortuito», dado que las leyes de composición determinan qué relaciones se componen y cuáles no se componen, pero «no determinan los cuerpos que se encuentran ni la manera en que se encuentran» ${ }^{66}$. Es en ese sentido que la historia es de la contingencia y no de la necesidad, como Deleuze afirma en numerosas oportunida- 
des. Pero, simultáneamente, la existencia de leyes de composición nos permite determinar cuándo la historia humana nos presenta un socius «tóxico» para los hombres que supuestamente debería socializar, como es el caso del capitalismo.

\section{Segunda triada: lo que puede un сuеrpo}

Dos órdenes diferentes para las esencias y los modos existentes. Deleuze habla también de «dos pisos» para la causalidad: la sustancia como causa de las esencias, los encuentros como causa de las existencias particulares ${ }^{67}$. ¿No retomamos entonces el problema que Strauss ha sabido plantear? La brecha que el tercer elemento de la teoría de la existencia nos había parecido cerrar, ¿no retorna entre los órdenes o los pisos? La ontología de Spinoza, ¿impide que nuestro mundo, nuestro medio presente, quede librado al azar? ¿Impide que los cuerpos y las almas se definan solamente por "sus encuentros y sus choques al azar»? ¿En qué medida el hecho de que las esencias se expresen en una relación característica cambia algo en lo que hace a la existencia particular del modo? Parecería que la cuestión no está suficientemente aclarada.

Ésta es la razón por la que Deleuze introduce una «segunda triada del modo finito» en su reconstrucción de la teoría spinozista de la existencia. Que ése sea el motivo de la tercera triada está lejos de ser evidente, pero Deleuze la anuncia explícitamente en el inicio del capítulo XIV de Spinoza y el problema de la expresión: «esta segunda triada del modo finito muestra bien cómo el modo expresa la sustancia, participa de la sustancia e, incluso, la reproduce a su manera» ${ }^{68}$. ¿Cómo expresa el modo a la sustancia? Es decir, ¿de qué manera la relación de correspondencia entre el modo y la sustancia, entre los dos pisos, entre los dos ór- denes, es decisivo para lo ontología, y por lo tanto para la política, de Spinoza? Veremos también que esta segunda triada se vincula, al mismo tiempo, con otro problema clave del spinozismo: de qué manera el modo existente que nosotros somos puede lograr formar ideas adecuadas (el asombro empirista). He aquí, nos dice Deleuze en el capítulo XIV, la «gran pregunta» ${ }^{69}$.

Si la primera triada estaba compuesta por la esencia natural, la existencia particular y la forma individual o relación característica, la segunda está compuesta de: 1) la esencia como grado de potencia; 2) un cierto poder de ser afectado en el cual ésta se expresa; 3 ) afectos que completan a cada instante ese poder ${ }^{70}$. Deleuze nos habla de un sistema de equivalencias entre las dos triadas. Hay que subrayar aquí la equivalencia entre el tercer elemento de la primera triada (la relación característica de un modo existente) y el segundo elemento de la segunda triada. Es en ese sentido que «Spinoza puede considerar como equivalente dos preguntas fundamentales: ¿Cuál es la estructura (fábrica) de un cuerpo? ¿Qué es lo que puede un cuerpo?». Veremos en qué sentido esta equivalencia es fundamental.

La tarea de solucionar el problema de la brecha entre esencia y existencia a través de esta nueva triada aparece llena de misterio. Sobre todo si consideramos que la primera cosa que hace Deleuze cuando trata esta pregunta es profundizar la grieta, enumerando las diferencias entre el modo existente y la sustancia divina ${ }^{71}$.

El segundo elemento de la segunda triada del modo finito nos dice que una esencia comporta «un cierto poder de ser afectado en el cual se expresa». Este poder de ser afectado del modo finito está «siempre completo». Pero no siempre de la misma manera. Y esto, porque hay dos tipos de afectos: activos y pasivos (dife- 
rencia que no es tomada en cuenta por Strauss en su estudio de Spinoza). A pesar de que la palabra «afecto» tiene una fuerte carga semántica de pasividad, en Spinoza hay afectos activos ( $\sin$ que ello constituya un oxímoron): «si suponemos afectos que se explican enteramente por la naturaleza del cuerpo afectado, estas afecciones son activas, son ellas mismas acciones»» ${ }^{72}$. Si, en cambio, la afección no se explica por la naturaleza del cuerpo afectado, el afecto es pasivo, es una «pasión».

Una afección pasiva que soportamos no es sino el efecto de un cuerpo sobre el nuestro. La idea de esta afección no expresa la causa, es decir, la naturaleza o esencia del cuerpo exterior... La afección de nuestro cuerpo es solamente una imagen corporal, y la idea de afección tal cual es en nuestro espíritu, una idea inadecuada o de la imaginación ${ }^{73}$.

La perspectiva empirista de Spinoza nos indica que las ideas que nos son dadas en primer lugar en tanto hombre, no son más que ideas inadecuadas: las ideas adecuadas no aparecerán más que como el resultado de una larga actividad a través de la cual las producimos:

En Spinoza, vale para la verdad como para la libertad: no están dadas en principio, sino que aparecen como el resultado de una larga actividad por la que producimos ideas adecuadas, escapando a la concatenación de una necesidad externa. Allí, la inspiración spinozista es profundamente empirista. Siempre es asombroso constatar la diferencia de inspiración entre los empiristas y los racionalistas. Los unos se asombran de lo que no asombra a los otros. Al decir de los racionalistas, la verdad y la libertad son ante todo derechos; se preguntan cómo podemos renegar de esos derechos, caer en el error o perder la libertad (...) En una perspectiva empirista, todo es invertido: lo asombroso es que los hombres lleguen a veces a comprender lo verdadero, a veces a comprenderse entre ellos, a veces a liberarse de lo que los encadena ${ }^{74}$.

El estado inicial de la «relación humana» es inadecuado. Deleuze señala que «Spinoza subraya que la infancia es un estado miserable» ${ }^{75}$. Nuestras ideas provienen entonces todas de los «choques») que nos llegan del exterior. Los sentimos, pero no los comprendemos. No conocemos su causa, es decir, «la naturaleza o la esencia del cuerpo exterior». No conocemos nada de él, de la relación que lo caracteriza. Los cuerpos exteriores conforman el afuera, pero se trata de un afuera terrible, un afuera hacia el cual no podemos osar salir a riesgo de ser exterminados. ¿Cómo saber que ante su relación la relación característica de nuestro cuerpo no será descompuesta, y por lo tanto seremos destruidos? Somos impotentes frente al afuera. Somos únicamente pasivos. Permanecemos entonces encerrados en nuestra interioridad. Habíamos dicho que lo que nos caracteriza según la segunda triada es un poder de ser afectado (que se corresponde con la relación que nos caracteriza según la primera triada): en tanto y en cuanto estamos en la impotencia, ese poder de ser afectado está en su grado más bajo, nuestra potencia humana no es más que potencia de padecer. Y sin embargo el grado de potencia que ese poder de ser afectado expresa es elástico, tiene un umbral mínimo pero también un umbral máximo:

Spinoza sugiere que la relación que caracteriza a un modo existente en su conjunto, está dotada de una especie de elasticidad (...) Como si poder y relación gozaran de un margen, de un límite en el que se forman y desforman. Ciertos pasajes de la Carta a Meyer adquieren aquí todo su sentido, que hace alusión a la existencia de un máximo y un mínimo ${ }^{76}$.

El encadenamiento a los afectos pasivos, las pasiones, no caracteriza al hombre, sino simplemente a la servidumbre humana: «Nuestra potencia de padecer es nuestra impotencia, nuestra servidumbre, es decir, el grado más bajo de nuestra potencia de actuar» ${ }^{77}$. No es más que humano. Así nacemos. Pero, 
¿quiere eso decir que estemos condenados a permanecer en la impotencia? Eso, únicamente, si sólo fuéramos capaces de ideas inadecuadas, de experimentar afectos activos, de actuar. Felizmente, no es tal el caso.

\section{Atravesando la brecha}

Habíamos dicho que seguía siendo misterioso de qué manera la segunda triada de la teoría de la existencia podría colmar la brecha entre esencia y existencia que el sistema de Spinoza parece establecer. Y, adicionalmente, la distancia entre Dios y los hombres se amplía respecto a las afecciones que completan el poder de cada uno, en la medida en que las ideas que le son dadas al hombre son siempre inadecuadas. Pero allí yace, justamente, el malentendido: el hecho de que las ideas que le son dadas al hombre sean siempre inadecuadas no quiere decir que el hombre sea capaz únicamente de ideas inadecuadas. Es verdad que, en la medida en que está afectado por pasiones, el hombre permanece separado de su esen$\mathrm{cia}^{78}$, y por lo tanto la brecha entre la sustancia y él está en su grado máximo. Estamos librados al azar de los encuentros. Padecemos. Nos caen encima como un rayo cosas que no comprendemos. Estamos condenados a la servidumbre. Estamos separados de lo que podemos.

A partir de la elasticidad de la relación que caracteriza al modo existente, la lectura de Deleuze de Spinoza propone la vía «empirista»: a partir del medio presente (a partir de lo inadecuado, a partir de la miseria, a partir de la superstición) intentar llegar a comprender lo verdadero, comprendernos entre nosotros, liberarnos de lo que nos encadena. No se trata de los sabios contemplando a la multitud. No se trata de una clase de hombres milagrosamente capaces de ideas adecuadas (sabios) y de otra condenada a las inadecuadas (multitud), como presenta la cuestión Strauss. No se trata de una teoría por un lado y de una religión por el otro irreconciliablemente escindidas. Sino de atravesar la brecha entre uno y otro umbral del grado de potencia que nos caracteriza a todos como hombres. De tensar el elástico de nuestra relación característica. Lo cual sólo será posible si somos capaces de afecciones activas, de ideas adecuadas y estuviéramos por lo tanto en pleno contacto con nuestra esencia (en tanto «en el modo existente, la esencia es lo mismo que su potencia de actuar» ${ }^{79}$ ). Es una bella interpretación del proyecto de Spinoza: se trata de cruzar la brecha entre esencia y existencia y restaurar así la potencia de las criaturas, su ser-activo, su posibilidad de actuar. He aquí el objetivo de la teoría del modo finito, según la interpretación que realiza Deleuze: «la idea misma de modo no es nunca un modo de retirarle toda potencia propia a la criatura: al contrario, según Spinoza, es el único modo de mostrar como las cosas "participan" de la potencia de Dios» ${ }^{80}$. Contra la empresa conjunta del cartesianismo y de la ciencia matemática y mecanicista de retirar «toda vitalidad o potencialidad a la Naturaleza», Spinoza se propone restaurar sus derechos ${ }^{81}$. Es en ese sentido que Spinoza nos permite entrever una posibilidad de liberación de la servidumbre humana, es decir, de la debilidad humana, de su pasividad.

La brecha del hombre respecto a la Sustancia y las esencias, en lugar de significar su liberación, es su servidumbre. Cortado de Dios y de su potencia, el hombre queda librado a la servidumbre de las causas exteriores y oscuras. Pensado como «sustancia», el hombre está condenado; de su orgullo deriva su condena. Tal es el quicio insuperable del humanismo. Solamente en tanto modo, sus derechos pueden ser restaurados. Un modo «conectado» con su esencia, que es la fuente de su conatus, la fuerza de per- 
severar en la existencia que proviene de Dios - lo no humano-. Pero sin necesitar para ello de la mediación de la Revelación, pues ese Dios no es trascendente.
He aquí la utopía deleuziana cuya clave es su spinozismo: conjunción de la filosofía o del concepto con el medio presente.

\section{NOTAS}

1 Deleuze, G., Différence et répétition, Paris, PUF, 1968, p. 177, la traducción es mía.

2 Strauss, L., Die Religionskritik Spinozas und zugehörige Schriften, Stuttgart, J. B. Metzler, 1996/2001, p. 54.

3 Strauss, op. cit., p. 401. Strauss habla allí de Calvino y Spinoza.

${ }^{4}$ Cf. Strauss, «Das Testament Spinozas», op. cit., p. 415 .

5 Cf. Deleuze, G. y Guattari, F., L'Anti-Oedipus, Paris, Minuit, 1972, p. 163.

${ }^{6}$ El interés en los escritos de Strauss sobre Spinoza se ha visto revitalizado por la aparición en 1996 en Alemania de Die Religionskritik Spinozas und zugehörige Schriften, op. cit. («La crítica a la religión de Spinoza y escritos relacionados») que compila todos los textos spinozistas hasta 1932, y la traducción casi inmediata al inglés y el francés de la mayoría de ellos. En Estados Unidos aparece Spinoza's critique of religión, trad. E. M. Sinclair, Chicago, University of Chicago Press, 1965. Los artículos de juventud fueron publicados en The Early Writings (1921-1932), New York, SUNY, 2002. Jewish Philosophy and the Crisis of Modernity, New York, SUNY, 1997, recupera «How to Study Spinoza's Theologico-Political Treatise» escrito en inglés para los Proceedings of the American Academy for Jewish Research 17 (1948). En Francia, Ami Bouganim realizó una compilación bajo el nombre Le testament de Spinoza, Paris, Nadir, 2000. Las traducciones son nuestras, a partir del original en alemán y la versión inglesa. La referencia se complementará con la indicación del año de publicación original de cada uno de los artículos: 1965 para el prefacio a la edición norteamericana de la Crítica, 1924 para «Cohens Analyse der Bibel-Wissenschaft Spinozas, 1926 para «Zur Bibelwissenschaft Spinozas und seiner Vorläufer» y 1932 para «Das Testament Spinozas».

7 Estos cursos han sido publicados en español bajo el título En medio de Spinoza, Buenos Aires, Cactus, 2006.

${ }^{8}$ Cf. por ejemplo, Ferry, L. et Renault, A., La pensée 68, Paris, Gallimard, 1985, y Lévy, B-H., La barbarie à visage humain, Paris, Grasset, 1977.

9 Strauss, op. cit. p. 369 (1924). Algunas páginas más adelante Strauss explicita el vínculo entre Spinoza y la tradición liberal: «La ciencia de la Biblia de Spinoza trata los mismos temas que ya eran cubiertos en parte por la tradición pero especialmente por el liberalismo», op. cit. p. 380 .

10 Strauss, op. cit. p. 390 (1926).

11 «El rechazo de Spinoza de la Ley reposa en el rechazo de la obediencia como tal, y reposa en última instancia en la ausencia de toda conciencia del pecado», op. cit. p. 403.

12 Strauss, «How to Study Spinoza's Theologico-Political Treatise», op. cit. p. 181.

13 Strauss, op. cit. p. 414.

14 Rivera García, A., «Secularización y crítica del liberalismo moderno», Isegoria, Revista de Filosofia Moral y Política, n. ${ }^{\circ}$ 39, julio-diciembre, 2008, pp. 81-82.

15 Ibid. En ese sentido, Deleuze sería absolutamente moderno, ya que todo el objeto de su filosofía política es la construcción de valores, criterios e instituciones de carácter inmanente, es decir, sin recurrir a una instanciación externa o trascendente (Ley, mandato, etc.).

16 Strauss, op. cit. p. 29 (1965).

17 «Denn mit dieser Voraussetzung ist die Kluft zwischen dem Weisen und der Menge gegeben» op. cit., p. 288, yo subrayo.

18 Ibid.

19 Strauss, op. cit., p. 292.

${ }^{20}$ Cf. Strauss, op. cit., p. 274. En el prefacio agregará: «No hay lugar en su pensamiento para la iluminación del pueblo. No tiene corazón por el pueblo, ni compasión», op. cit., p. 34 (1962).

21 Strauss, op. cit., p. 280.

22 Strauss, op. cit., p. 294.

23 Deleuze, G., En medio de Spinoza, op. cit., p. 136.

24 Cf. Strauss, op. cit., p. 391-392 (1926).

25 Strauss, op. cit., 392 (1926).

26 Strauss, «How to...», op. cit., p. 208.

27 Strauss, Die Religionskritik..., op. cit., p. 422 (1932). Esta interpretación difiere habitual, que es considerar que Strauss valora el testamento que habría dejado Spinoza: independencia. Cf. Lastra, A., La naturaleza de la filosofía política, un ensayo sobre Leo Strauss, Murcia, Res Publica, 2000, p. 43, y Molas, J., «Strauss y Spinoza», en Cuadernos del seminario Spinoza, n. ${ }^{\circ}$ 13, Ciudad Real, 2002, p. 15.

28 Cf. Strauss, op. cit. pp. 395 y 398.

29 Strauss, op. cit. p. 307.

30 Spinoza, B., «Carta XII a Meyer», en Correspondencia, Madrid, Alianza Editorial, 1988, pp. 130-131. 
31 Deleuze, Spinoza et le problème de l'expression, Paris, Minuit, 1968. Hay traducción al español de H. Vogel, Barcelona, Muchnik, 1996, que tomamos con algunas modificaciones a partir del original en las citas más extensas, atribuyendo la traducción a través de la indicación del número de página de la edición en castellano entre paréntesis. En las citas breves, la traducción es mía.

32 Deleuze, G., Préface à l'Anomalie Sauvage d'Antonio Negri, en Deux régimes de fous, Paris, Minuit, 2003, p. 177.

33 «Spinoza renuncia así a todo intento de reconciliar religión - tal como él la entiende y reconoce, y tal como cree que la encuentra en la Escritura - con sus principios, que simplemente excluyen toda posibilidad de la Revelación. La interpretación debe intentar lograr lo que Spinoza omitió, debe intentar mostrar cómo, a partir de sus principios, su teoría de la religión debe ser entendida», Strauss, op. cit., p. 308 , «Dios gravó Su palabra eterna en los corazones humanos. Esta palabra requiere de nosotros amor y justicia, y nada más. Esa es la religión verdadera, universal y natural», Strauss, op. cit., pp. 311-312.

34 Strauss, op. cit., p. 288.

35 De acuerdo a la interpretación de Rivera García, la acusación recaería sobre el mismo Strauss, ya que «en oposición al igualitarismo de los nuevos tiempos, nuestro filósofo [Strauss], como enemigo declarado de la democracia radical, llega a escribir que "es una exigencia de la justicia que exista una correspondencia razonable entre la jerarquía social [o política] y la jerarquía natural" que distingue entre sabios e ignorantes», Rivera García, op. cit., p. 91. La cita de Strauss es de Liberalismo antiguo y moderno, Buenos Aires, Katz, 2007, p. 40. Decidir si esa frase está o no indicando la posición de Strauss implicaría entrar en un análisis que excede el recorte aquí propuesto (la obra de Strauss en torno a Spinoza).

36 Strauss, op. cit., p. 52 (1962).

37 Lastra, A., La naturaleza de la filosofia política, un ensayo sobre Leo Strauss, Murcia, Res Publica, 2000 , p. 31.

38 Deleuze y Guattari, op. cit., p. 350.

39 Dotti, J., «Filioque», en Schmitt, C., La tiranía de los valores, Buenos Aires, Hydra, 2009, p. 70. Toda la introducción de Dotti al opúsculo de Schmitt gira en torno a una problemática similar a la presentada en este artículo: la desconfianza en los valores e instituciones inmanentes de la modernidad. El pensamiento de Strauss es por cierto uno de los objetos de estudio de Dotti.

40 Cf. Strauss, op. cit., p. 54 (1965).

41 Para Strauss, según el análisis de Rivera García, el entendimiento ha pagado el precio de «la renuncia a lo que da sentido a la vida, a plantear la cuestión del verdadero bien» (op. cit., p. 98). Deleuze distingue la cuestión del «sentido de la vida» (lo ultra-humano) y la del bien.

42 Strauss, op. cit., p. 51 (1962). Como bien analiza A. Rivera García, «la tolerancia liberal estaba obli- gada a admitir como posible la opción del adversario», op. cit., p. 88.

43 Deleuze, Spinoza et le problème de l'expression, op. cit., p. 177. «Hay un orden de las esencias, determinado por los grados de potencia. Este orden es un orden de conveniencia total: cada esencia conviene con todas las otras», op. cit., p. 216.

44 Strauss, op. cit., p. 32 (1965).

45 Deleuze, op. cit., p. 183 (193).

46 Deleuze, En medio de Spinoza, op. cit., p. 144.

47 Cf. Strauss, op. cit., p. 292.

48 Deleuze, Spinoza et le problème de l'expression, op. cit., p. 134.

49 Strauss, op. cit., p. 32 (1965).

50 Ibid.

51 «Yo debo tener un cuerpo, es una necesidad moral, una "exigencia"», Deleuze, G., Le pli, Leibniz et le baroque, Paris, Minuit, 1988, p. 113.

52 Deleuze, Spinoza et le problème... op. cit., p. 181

53 Deleuze, op. cit., p. 184.

54 Para evitar estos malentendidos, «la palabra alma sólo es utilizada en la Etica en ocasiones excepcionales y polémicas. Spinoza sustituye por ella la palabra mens» (op. cit., p. 92). Estos malentendidos son especialmente notables en francés donde no existe una palabra equivalente a mente (sprit es lo más cercano, pero se presta obviamente a otros malentendidos).

55 Cf. Deleuze, op. cit., p. 191. La primera triada se desarrolla en el capítulo XIII (pp. 191-196). La segunda ocupa el capítulo XIV.

56 Deleuze, op. cit., p. 191.

57 Deleuze, op. cit., p. 190.

58 Deleuze, op. cit., p. 191 (202).

59 Deleuze, op. cit., p. 195.

60 Deleuze, op. cit., p. 193.

61 Ibid.

62 Deleuze, op. cit., p. 215.

63 Deleuze, op. cit., pp. 216-217 (229).

${ }^{64}$ Deleuze, op. cit., pp. 192-193 (202-203).

65 «La prohibición del fruto del árbol consistía solamente en la revelación hecha por Dios a Adán de las consecuencias mortales que tendría la ingesta de ese fruto; es así que nosotros sabemos por la luz natural que un veneno trae la muerte», Spinoza, carta XIX a Blyenbergh, en Traité politique et Lettres, trad. Ch. Appuhn, Paris, GF Flammarion, 1966, p. 185. Citado en Spinoza, philosophie pratique, Paris, Minuit, 1981, p. 45.

66 Deleuze, Spinoza et le problème de l'expression, op. cit., p. 217.

${ }^{67}$ Cf. Deleuze, op. cit., p. 194.

68 Deleuze, op. cit., p. 198.

69 «La gran pregunta que se plantea a propósito del modo existente finito es entonces: ¿lograremos afectos activos, y cómo?», Deleuze, op. cit., p. 199.

70 Cf. Deleuze, op. cit., p. 197.

71 Cf. Deleuze, op. cit., pp. 198-199.

72 Deleuze, op. cit., p. 198. 
73 Deleuze, op. cit., p. 199 (pp. 210-211).

74 Deleuze, op. cit., p. 134 (144).

75 Deleuze, op. cit., p. 199.

76 Deleuze, op. cit., p. 202 (214).

77 Deleuze, op. cit., p. 204.

78 «En la medida en que está completo por afectos pasivos, [el poder de ser afectado] está reducido al mí- nimo; permanecemos entonces imperfectos e impotentes, estamos de alguna manera separados de nuestra esencia y de nuestro grado de potencia, separados de lo que podemos», Deleuze, op. cit., p. 205.

79 Deleuze, op. cit., p. 205.

80 Deleuze, op. cit., p. 207.

81 Deleuze, op. cit., p. 207. 